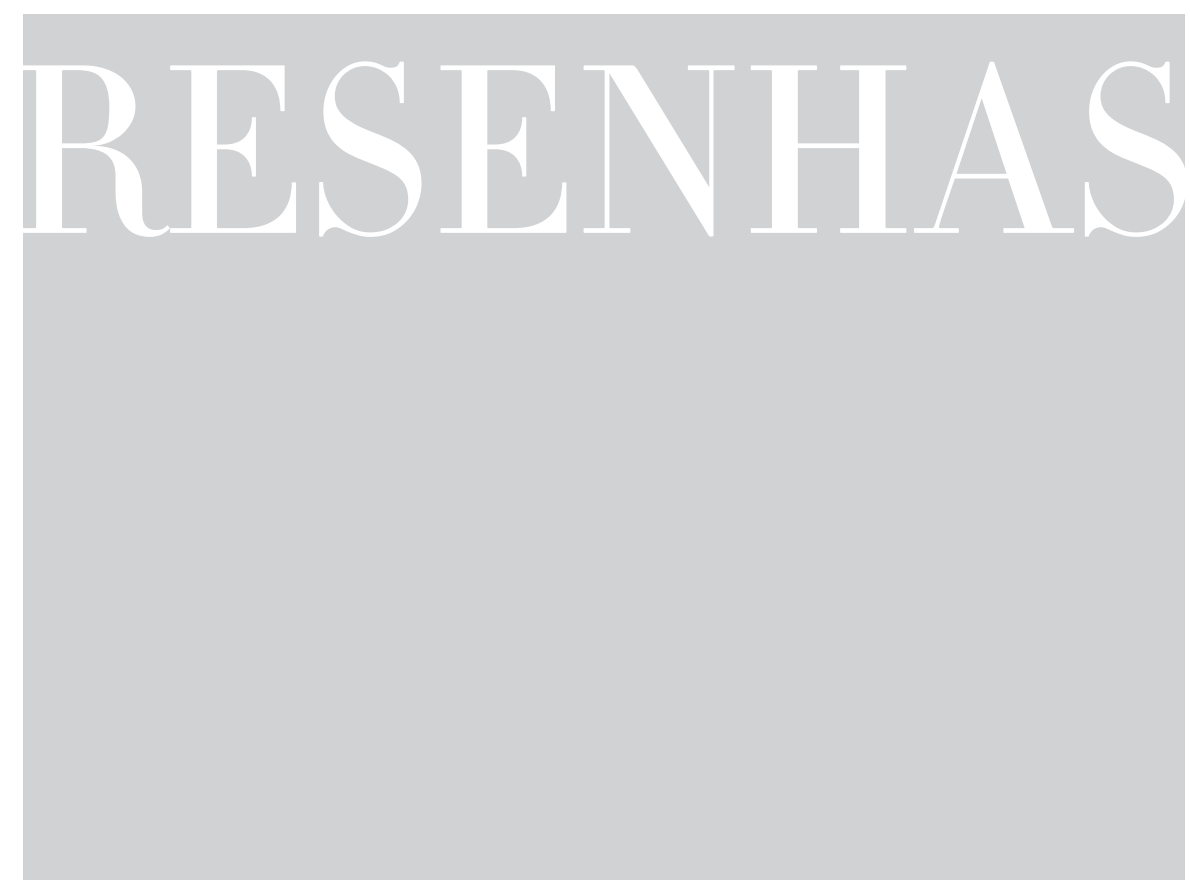

\title{
A EDUCAÇÃO NAS TRAJETÓRIAS DAS DESIGUALDADES'
}

ARRETCHE, Marta (Org). Trajetórias das desigualdades: como o Brasil mudou nos últimos cinquenta anos. São Paulo: Editora Unesp; CEM, 2015. 489p.

Analisar a trajetória das desigualdades do Brasil nos últimos cinquenta anos foi o projeto bem-sucedido organizado por Marta Arretche, do Centro de Estudos da Metrópole/Centro Brasileiro de Análise e Planejamento - CEM/Cebrap. ${ }^{2}$ O termo desigualdades foi cunhado no plural como argumento central que costura as múltiplas configurações presentes no livro e que não se esgotam apenas na desigualdade de ren-

\section{1}

As autoras agradecem à orientadora Profa. Dra. Maria da Graça Setton e aos colegas do Grupo de Estudos de Práticas de Socialização

Contemporâneas pela discussão coletiva de alguns capítulos do livro e pelo acesso a suas anotações.

O CEM é uma instituição de pesquisa com sede na Universidade de São Paulo e no Cebrap, composta por um grupo multidisciplinar de pesquisadores. Conferir o site oficial: http://www.fflch usp.br/centrodametropole/1. Acesso em: 19 mar. 2016. da. Diversos autores, na sua maioria cientistas sociais e economistas do eixo São Paulo-Rio de Janeiro, se debruçaram sobre os dados do Instituto Brasileiro de Geografia e Estatística - IBGE - para analisar o processo de desenvolvimento econômico e social a partir de séries históricas e estatísticas entre os anos de 1960 e 2010. O trabalho primoroso no tratamento dos dados caracteriza a obra como uma referência para as ciências sociais. De forma geral, o livro mostra como as desigualdades diminuíram ao longo desse período, contrariando o senso comum sobre a realidade brasileira. Sobre a apresentação técnica, o livro contém muitos gráficos e tabelas, alguns de difícil compreensão por estarem em escala de cinza.

Um dos ganhos significativos foi utilizar dados do IBGE de gênero e raça. Essa separação afinou as análises por permitirem esmiuçar 
como as transformações e continuidades se deram nessas categorias. Demonstrou-se, por um lado, a persistência da desigualdade racial e, por outro, a diminuição da desigualdade de gênero. Evidentemente, ainda há muito espaço para conquista das mulheres, principalmente na questão salarial. Se os dados fossem analisados de maneira generalizada, perderiam essa importante nuance que caracteriza a sociedade brasileira. Poder-se-ia, porém, aprofundar o estudo separando os não brancos por gênero, pois uma pergunta relevante que não foi respondida na obra é: qual é a posição das mulheres negras e indígenas, visto que estão na posição menos privilegiada?

A obra se divide em cinco partes: I. da participação política; II. da educação e renda; III. das políticas públicas; IV. da demografia e V. do mercado de trabalho. Ao longo dos textos é possível perceber que tais dimensões se articulam, comprovando a tese central da existência e persistência das desigualdades plurais do Brasil.

Sobre o campo educacional, o livro traz resultados importantes para a reflexão teórica daqueles que buscam analisar a educação de forma relacional, levando em conta a configuração social brasileira. Engana-se quem, em um primeiro momento, considere que apenas os artigos da seção “Educação e renda” trarão contribuições para tal. Evidentemente, essa parte é a mais direta. Contudo, a educação foi um dos componentes-chave para interpretar muitos dos resultados apresentados ao longo da obra.

Na primeira parte, por exemplo, o artigo "Participação política no Brasil”, de Fernando Limongi, José Cheibub e Argelina Figueiredo, mostrou como o fator educacional influenciou na transformação da decisão política pela participação eleitoral dos analfabetos excluídos do processo decisório até a Constituição de 1988. O artigo "Saúde e desigualdade no Brasil”, de Vera Coelho e Marcelo Dias, revelou que mulheres com 15 anos ou mais, que tenham ensino fundamental completo, contribuíram para a queda da taxa de mortalidade infantil e para o aumento da taxa de esperança de vida ao nascer. Desse modo, atrelada à renda média dos municípios, a escolarização feminina demonstrou ser importante para os indicadores da saúde.

A educação feminina possui destaque também no artigo “Cinquenta anos de relações de gênero e geração”, de Marcia Oliveira, Joice Vieira e Glaucia Marcondes. As autoras mostraram que a educação, nas últimas décadas, promoveu uma redução das desigualdades. Aliada ao acesso de políticas públicas para a saúde e a métodos contraceptivos, a mulher escolarizada passou a escolher se quer ser mãe. Essa escolha cada vez mais racional ocasionou a redução da taxa de fecundidade e a postergação da gravidez, que, combinada à entrada das mulheres no mercado de trabalho e à urbanização, levou a uma redução das desigualdades sociais e regionais históricas, embora ainda haja um longo caminho para a igualdade de gêneros. 
Por fim, o último exemplo consiste no artigo "Desenvolvimento econômico e desigualdades no Brasil: 1960-2010”, de Alvaro Comin, que tratou das mudanças estruturais consequentes do desenvolvimento econômico que afetaram as desigualdades ocupacionais no Brasil. A questão educacional também tangencia a análise em vários aspectos. Quando um grande contingente da população rural, analfabeta ou com pouca escolaridade, migrou para a cidade, não conseguiu se inserir no mercado de trabalho formal. Ao longo do desenvolvimento econômico, houve ampliação educacional gradual dessa força de trabalho, aumentando a renda das famílias da base da pirâmide ocupacional e a produtividade econômica a partir de trabalhadores mais qualificados. A desigualdade entre homens e mulheres diminuiu em alguns setores, especialmente por causa da escolaridade feminina, mas evidentemente ainda não se equalizou a questão de gênero.

\section{A EDUCAÇÃO NAS TRAJETÓRIAS DA DESIGUALDADE}

Na segunda parte da obra, denominada de "Educação e Renda", os autores se debruçaram sobre a questão educacional de forma mais específica. O artigo "Estratificação educacional entre jovens no Brasil: 1960 a 2010”, de Carlos Ribeiro, Ricardo Ceneviva e Murillo de Brito, teve como objetivo avaliar a estratificação a partir do modelo de progressão educacional. O recorte utilizado foi dos jovens entre 12 e 25 anos, cruzando os dados das características socioeconômicas das famílias e as chances de progresso nos níveis de ensino a partir de variáveis que se assemelham àquelas utilizadas por Bourdieu em “A escola conservadora” (2003). O interessante é notar como os dados se articularam: a escolarização das mulheres aumentou em relação aos dos homens; a escolarização dos pardos se aproximou à dos brancos, mas os pretos continuaram com menores chances de renda; a escolaridade da mãe e a composição familiar influenciaram na progressão educacional; por fim, a variável situação de residência operou em todos os níveis educacionais e em todas as faixas etárias.

Os resultados podem ser compreendidos por meio da análise do impacto de cada uma das variáveis sobre as chances de sucesso de completar determinada transição escolar e também a partir da transição de um período histórico. Por exemplo, o fato de pertencer a uma família monoparental foi um quesito importante nas décadas de 1960 e 1990, mas, a partir de 2000, essa variável deixou de ser relevante. A análise indicou que, no nível básico, as oportunidades de acesso aumentaram, enquanto as desigualdades persistiram no ensino médio e aumentaram no nível superior. Dito de outra forma, a desigualdade diminui apenas quando as taxas de transição atingem níveis de saturação que impedem aumento entre as classes mais privilegiadas. 
O artigo "Educação e desigualdades no Brasil", de Naercio Menezes Filho e Charles Kirschbaum, analisou como o nível educacional de diferentes trabalhadores afetou os salários e a desigualdade de renda no mercado de trabalho nos últimos quarenta anos. Os autores concluíram que a educação afetou a mudança social por influenciar na criminalidade, cidadania, na fertilidade, além de impactar o mercado de trabalho. Apontou-se no artigo que as mudanças de acesso ao ensino básico foram possíveis por causa da descentralização da gestão a partir da Constituição Federal de 1998, dos fundos de financiamento da educação, além de programas de transferência de rendas. O prolongamento dos estudos ao nível superior foi possível pela abertura de novas faculdades particulares por causa das regras de flexibilização para abertura de novas instituições. Quanto ao gênero, os autores mostraram que os homens têm renda mais elevada, mas a renda das mulheres cresceu mais do que a dos homens no período analisado. Sobre raça, os brancos e amarelos estão nos estratos educacionais mais elevados, por isso sua renda é mais elevada que a dos pretos e pardos, mesmo dos que estão nos mesmos estratos educacionais, refletindo a discriminação no mercado de trabalho. Os negros também recebem a educação de menor qualidade, pois a maioria estuda em escolas públicas.

O artigo "Estratificação horizontal da educação superior no Brasil (1960 a 2010)”, de Carlos Ribeiro e Rogerio Schlegel, trouxe uma análise em profundidade das continuidades e transformações desse nível educacional. As diferenças entre as instituições públicas e privadas, assim como a qualidade e reputação dessas últimas, influenciaram na carreira universitária e, consequentemente, nos melhores postos de trabalhos. O prolongamento dos estudos foi um marcador da estratificação social, pois os mais privilegiados conseguem estudar por mais tempo, nas melhores instituições e na companhia de pessoas igualmente privilegiadas.

Os dados mostraram como se configuraram as carreiras pelo gênero. Como tem sido tradicionalmente, os homens estão nas carreias de exatas e negócios enquanto as mulheres, nas ciências humanas, arte, educação e saúde. No entanto, ao longo dos cinquenta anos, essa assimetria diminuiu, crescendo o número de mulheres em carreiras antes de hegemonia masculina. Essas escolhas se restringiram mais aos brancos, pois o acesso ao ensino superior aos negros e indígenas seguem sendo bem limitados. Para estes, houve um aumento tímido do acesso nas carreiras de menor prestígio e de escolhas de carreiras que se caracterizaram como sendo femininas. De forma geral, houve um aumento do acesso ao ensino superior representado pela expansão das mulheres nesse nível, enquanto houve um pequeno crescimento de não brancos, não de maneira igualitária entre as carreiras. A forte estratificação horizontal no sistema de ensino superior no Brasil é observada tanto na conclusão dos cursos como nos retornos aos cursos no mercado de trabalho (ainda desiguais nas variáveis de gênero e raça). 
O último artigo sobre educação e renda denomina-se "Desigualdades raciais no Brasil: um desafio persistente”, de Márcia Lima e Ian Prates. Esse texto aprofundou as análises dos artigos anteriores sobre raça. Os autores analisaram as transformações oriundas da posse de diplomas segundo cor/raça no período de 1980 a 2010. Embora o acesso à educação formal seja um mecanismo produtor de desigualdades que afeta a desigualdade racial, recentemente as políticas de ação afirmativa para o ensino superior têm sido especialmente importantes para a diminuição dessas desigualdades, uma vez que a posse do diploma superior dos pais tem impacto decisivo no alcance educacional dos filhos. As conclusões de Lima e Prates revelaram a dificuldade de mobilidade social dos negros e a forte capacidade de reprodução da situação por estarem na base da pirâmide social, haja vista que as dificuldades educacionais segundo a classe se sobrepõem às barreiras raciais. No que tange ao progresso educacional, revelou-se que, enquanto o efeito de classe de origem tende a diminuir na transição das etapas educacionais, o efeito racial tende a aumentar na transição para os níveis mais altos. Os dados mostraram melhoras pequenas, mas, como indicaram no artigo, esse é um “desafio persistente”.

\section{CONSIDERAÇÕES FINAIS}

Educação e desigualdades são temas clássicos na área da educação no Brasil. Esse viés de análise tem forte influência da sociologia francesa, que partiu da contribuição da obra clássica de Bourdieu e Passeron (1964, 2014), que tomam os capitais culturais e simbólicos para analisar as diferenças no interior do sistema de ensino. No contexto brasileiro, muito se adaptou e evoluiu dessa perspectiva teórica.

Dessas transformações, uma tendência que vem se realizando é o “assalto à educação pelos economistas”, crítica de Ana Maria Almeida (2008), que alerta que:

\footnotetext{
[...] a educação escolar é mais uma vez tomada como "variável explicativa" fundamental e chamada a oferecer a sua contribuição específica para o problema da nação. Como tal, ela passa a ser percebida como uma das arenas em que a competência dos economistas deve se exercer. (p. 163-164)
}

Por isso é importante utilizar-se dos dados sobre educação do livro de Marta Arretche com o cuidado teórico para que tal crítica nos adverte.

De forma geral, a obra nos ajuda a obter maiores informações sobre o processo de desenvolvimento social e econômico no Brasil, além de nos dar ferramentas para acompanhar o levantamento acerca da estrutura social, sua dinâmica e fatores que interferem nas transformações 
de elementos que compõem variáveis da sociologia. São evidentes as mudanças na nossa organização social e tudo leva a crer que as desigualdades diminuíram e foram na direção oposta da maioria dos países capitalistas. Contudo, ainda há muito o que se fazer. Ao concluir que as desigualdades diminuíram principalmente pelas conquistas femininas, falamos do empoderamento de mulheres negras e brancas para um protagonismo social cujo impacto não pode ser medido a olho nu e nem de imediato. Como dizem os autores, trata-se de uma revolução silenciosa.

Por fim, é importante afirmar que a diminuição das desigualdades se deu fundamentalmente devido a um feixe de políticas públicas combinado com uma mudança de comportamentos e com a democracia. É nesse tripé que podem se apoiar os esforços para a diminuição das desigualdades para os próximos 50 anos.

\title{
REFERÊNCIAS
}

ALMEIDA, Ana Maria F. O assalto à educação pelos economistas. Tempo Social, v. 20, p. 163-178, 2008.

BOURDIEU, Pierre. A escola conservadora. In: BOURDIEU, Pierre. Escritos da Educação. Petrópolis: Vozes, 2003. p. 41-64.

BOURDIEU, Pierre; PASSERON, Jean-Claude. Os herdeiros: os estudantes e a cultura. Florianópolis: Editora da UFSC, 2014. 1ª edição de 1964.

\author{
ADRIANA SANTIAGO ROSA DANTAS \\ Doutoranda em Sociologia da Educação na Faculdade de Educação da \\ Universidade de São Paulo - FE/USP -, São Paulo, São Paulo, Brasil; bolsista da \\ Fundação de Amparo à Pesquisa do Estado de São Paulo - Fapesp -, São Paulo, \\ São Paulo, Brasil \\ novadrica@gmail.com
}

\section{GABRIELA ABUHAB VALENTE}

Doutoranda em Sociologia da Educação na Faculdade de Educação da Universidade de São Paulo - FE/USP -, São Paulo, São Paulo, Brasil; bolsista da Fundação de Amparo à Pesquisa do Estado de São Paulo - Fapesp -, São Paulo, São Paulo, Brasil gabriela.abuhab.valente@gmail.com 